\title{
Analysis of EPA's Cost-Effectiveness Study for the Coastal Oil and Gas Effluent Limitations Guidelines
}
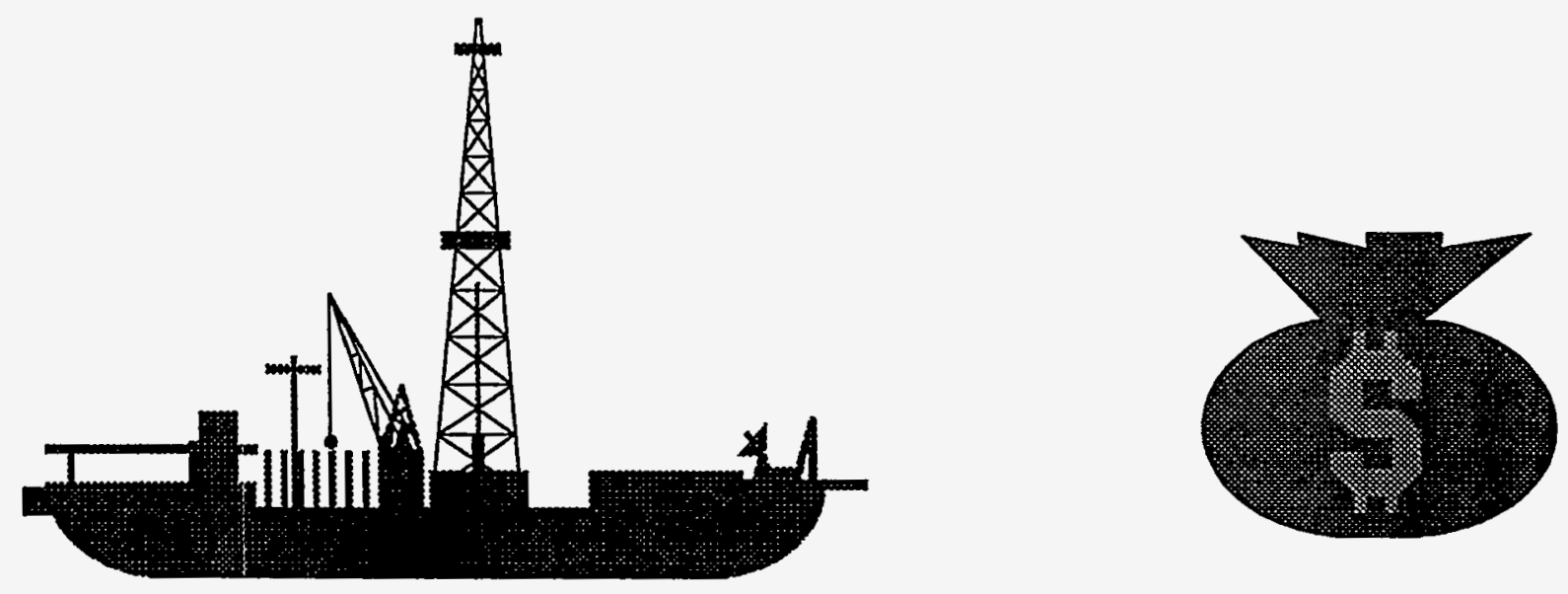

Prepared for:

U.S. Department of Energy

Office of Policy and Office of Fossil Energy under Contract W-31-109-ENG-38

Prepared by: John Veil

Argonne National Laboratory

Washington, DC

May 1995

DISTRIBUTION OF THIS DOCUMENT IS UNLMMTED GH 


\section{DISCLAIMER}

Portions of this document may be illegible in electronic image products. Images are produced from the best available original document. 


\section{Executive Summary}

The U.S. Environmental Protection Agency (EPA) conducted a cost-effectiveness (CE) analysis to estimate the incremental cost of complying with the proposed effluent limitation guidelines (ELGs) for the coastal oil and gas industry (EPA 1995a). EPA's CE analysis calculates the pounds of each pollutant that would be removed if the chosen discharge option is selected. The number of pounds of each pollutant is converted to pound equivalents (PEs) by multiplying the pounds by a weighting factor to account for the different degree of environmental impact associated with each pollutant. Weighting factors are derived from a combination of aquatic life protection and human health protection values. Where possible, EPA uses its published water quality criteria as the necessary values. If criteria are not available, EPA searches the literature to find other reported data that can be used to estimate the values.

In 1993, EPA issued final ELGs for the offshore oil and gas industry and published an offshore $\mathrm{CE}$ analysis. The chemical characteristics of produced water from the offshore region are essentially the same as those of produced water from the coastal region. It was surprising, therefore, that EPA chose a much longer list of pollutants and generally stricter weighting factors for the coastal $\mathrm{CE}$ analysis. This report reviews the data, assumptions, and analyses used in EPA's coastal CE analysis and identifies alternate data, assumptions, and analyses that could lead to significantly different cost-effectiveness conclusions.

Two alternate lists of pollutants are proposed, along with recalculated weighting factors for several pollutants that contributed a large proportion of the total PEs removed -- radium, benzo(a)pyrene, boron, and ammonia. By using different combinations of these variables, a range of revised estimates of $\mathrm{CE}$ is calculated.

EPA calculates that the proposed discharge requirements for produced water will cost \$4/PE. EPA compares this value to other industries for which the CE analysis has been done and concludes that the proposed requirements are cost-effective. However, the recalculated scenarios presented in this report find the CE to be as high as \$143/PE, with a more realistic range being $\$ 87 / \mathrm{PE}-\$ 92 / \mathrm{PE}$. At these higher levels, the coastal produced water requirements are more costly than those for most other industries.

\section{DISCLAIMER}

This report was prepared as an account of work sponsored by an agency of the United States Government. Neither the United States Government nor any agency thereof, nor any of their employees, makes any warranty, express or implied, or assumes any legal liability or responsibility for the accuracy, completeness, or usefulness of any information, apparatus, product, or process disclosed, or represents that its use would not infringe privately owned rights. Reference herein to any specific commercial product, process, or service by trade name, trademark, manufacturer, or otherwise does not necessarily constitute or imply its endorsement, recommendation, or favoring by the United States Government or any agency thereof. The views and opinions of authors expressed herein do not necessarily state or reflect those of the United States Government or any agency thereof. 
Introduction

The U.S. Environmental Protection Agency (EPA) conducted a cost-effectiveness (CE) analysis to estimate the incremental cost of complying with the proposed effluent limitation guidelines (ELGs) for the coastal oil and gas industry (EPA 1995a). This report reviews the data, assumptions, and analyses used in EPA's coastal CE analysis and identifies alternate data, assumptions, and analyses that could lead to significantly different cost-effectiveness conclusions. Although EPA (1995a) presents CE analyses for three major oil and gas waste streams, this report reviews and critiques just the $\mathrm{CE}$ analysis for produced water. EPA's $\mathrm{CE}$ analyses for the other two waste streams: a) drilling fluids and drill cuttings, and b) well treatment, workover, and completion fluids already demonstrate elevated \$/PE figures.

EPA's definition of the CE methodology and guidance on its use are provided in Ehrensberger and Rico (1988). CE is defined as the incremental annualized cost of a pollution control option in an industry per incremental pound equivalent (PE) of pollutant removed annually by that control option. When calculating annual pollutant removal, the relative effects of the different pollutants must be considered. One way of scaling different pollutants is to assign a weighting factor to each pollutant based on its toxicity. EPA's methodology calculates weighting factors using EPA's ambient water quality criteria for chronic aquatic life protection (fresh or salt water) and for human health protection from exposure through fish consumption. For carcinogenic pollutants, the risk factor is taken as $10^{-5}$. All pollutants are normalized to a standard of $5.6 \mathrm{ppb}$, the aquatic life protection criterion for copper at the time the methodology was developed. Equation 1 shows the formula used.

$$
\text { weighting factor }=5.6 / \mathrm{AL}+5.6 / \mathrm{HH} \text {, where }
$$

$\mathrm{AL}=$ aquatic life protection criterion and

$\mathrm{HH}=$ human health protection criterion.

A more toxic pollutant has lower criteria resulting in a higher weighting factor.

The next step in the procedure is multiplication of the anticipated pounds removed by the weighting factors to obtain PE removed. Since CE is calculated on an incremental basis, the $\mathrm{PE}$ must be calculated separately for each pollution control option. The incremental PE is the $P E$ for the option under consideration minus that for the next less stringent option. Costs must also be calculated on an incremental basis. The CE (expressed as \$/PE) is then calculated by dividing the incremental annualized cost by the incremental PE. In the CE analysis, all costs are expressed in 1981 dollars to allow comparison with other industries. EPA is not legally bound by the results of a CE analysis; however, if the \$/PE for a proposed regulation is calculated to be significantly higher than the \$/PEs for other comparable regulations, EPA might be reconsider its proposal.

The list of pollutants used in the CE analysis is not limited to those pollutants regulated by the effluent guidelines. The list also contains selected other toxics or non-conventional non- 
toxics that will be removed by a treatment option. For example, for drilling fluids and drill cuttings, only mercury and cadmium are limited in the proposed effluent guidelines, but many other metals will be removed by the treatment options.

\section{General Weaknesses in the CE Methodology}

Veil (1992) discusses the general weaknesses of the CE methodology that apply to all industries. Since these weaknesses apply consistently to all other industries for which a CE analysis has been done, they are discussed here only briefly.

The first general weakness is the use of weighting factors to account for different environmental impacts of various pollutants. The concept of applying weighting factors is valid, but the method of estimating or assigning weighting factors is critical. Ideally, EPA would have developed a full suite of aquatic life protection and human health protection criteria for all pollutants considered in the $C E$ analysis, but such criteria are frequently not available. In many cases, EPA must derive weighting factors using toxicological data that has not been peerreviewed or subject to the national scrutiny required for full criteria development. EPA has not been consistent on the weighting factors calculated for similar industries (e.g., offshore oil and gas vs. proposed coastal oil and gas) even though both industries' discharges contain the same set of pollutants and the weighting factors were calculated only two years apart. This subject is discussed in greater detail in a later section.

The second general weakness is the need to sum the effect of aquatic life protection criteria and human health protection criteria rather than using whichever criterion will result in a larger weighting factor. This practice serves to make the weighting factor larger, especially if the two criteria are approximately equal.

The third general weakness is the use of an incremental approach rather than a cumulative approach. When several treatment options are being considered, costs and PE removed are calculated for each option. \$/PE are then incrementally calculated. This approach is dependent on the number of options under consideration. While for most industries only a few treatment options are considered, the more options that are considered, the less meaningful the incremental approach becomes. EPA calculates the \$/PE both incrementally and cumulatively in the coastal $C E$ analysis, although it still only uses the incremental $\$ / P E$ in its comparisons to other industry.

The final area of general weakness is the failure to consider the form of metal used in the calculations. Until recently, most water quality calculations considered the total or total recoverable form of metals. EPA's most recent guidance on the issue (Prothro, 1993) states:

"It is now the policy of the Office of Water that the use of dissolved metal to set and measure compliance with water quality standards is the recommended approach, because dissolved metal more closely approximates the bioavailable fraction of metal in the water column than does total recoverable metal." 
Under the Prothro policy, permit limits must still be expressed as total or total recoverable metals. Because the $\mathrm{CE}$ analysis considers the total quantity of metals being discharged, it overestimates the number of pounds of biologically available metals that are being discharged. A good example of this from the coastal oil and gas subcategory is barium sulfate which is a major component of drilling fluid discharges. Barium sulfate is relatively insoluble and very little of the barium will be found as dissolved barium. In produced water, barium is found in a dissolved form, but following discharge to saline waters, it rapidly precipitates to form an insoluble barium compound. Nevertheless, all of the barium for both waste streams is reported as being discharged.

Attachment 2 to Prothro (1993) contains data on the percentage of total recoverable metals that have been measured as dissolved metals. This attachment recommends values for the percentage of total recoverable metal that is in the dissolved form ranging from $25 \%-95 \%$. This data in Attachment 2 is solely fresh water data, and therefore is not directly relevant to salt water. But the concept that metals associated with drilling fluids and produced water are not completely soluble is applicable to salt and brackish water also.

\section{Specific Weaknesses in the CE Analysis for the Coastal Oil and Gas Subcategory}

The specific weaknesses in the coastal $\mathrm{CE}$ analysis are in the areas of selection of pollutants and calculation of weighting factors. No attempt has been made to recalculate the cost estimates used in EPA's CE analysis, although it is worth noting that in several previous rulemakings, EPA's estimates of costs have been substantially lower than the costs estimated by DOE and industry.

\section{Selection of Pollutants}

\section{Comparison to Offshore ELGs}

The selection of pollutants used to calculate pounds removed for the CE analysis for produced water are based on data collected by EPA at ten Gulf of Mexico production facilities (SAIC 1994) and on several other studies for Cook Inlet. Since the majority of the produced water pollutants that would be removed under EPA's chosen option 4 would come from Gulf of Mexico dischargers, comments are limited to the Gulf of Mexico data. The most notable thing about the 10-facility study is the large number of pollutants for which data was collected. Table VIII-4 from the coastal Development Document (EPA, 1995b) lists data for 22 priority pollutants and 53 other pollutants. This contrasts with Table IX-15 in the offshore Development Document (EPA, 1993a) that lists a total of 32 pollutants. This should not suggest that the produced water in the offshore subcategory is significantly different and cleaner than produced water from the coastal subcategory. Instead, this is a function of a more detailed sampling program.

When the two lists of pollutants are converted into pounds of pollutants discharged. the coastal list will have a much higher total pound loading by virtue of: a) a larger number of 
pollutants, and b) inclusion of non-toxic "pollutants" that are basic components of natural coastal waters like chlorides, magnesium, and calcium. This is demonstrated in Table 1, which combines the data from pages A-3 - A-6 of the coastal CE analysis. Table 1 shows that over 4 billion pounds of pollutants would be removed under EPA's option 4. By comparison, a similar table, Table 2, was generated using only those pollutants considered in the CE analysis conducted for the offshore subcategory (EPA, 1993b). In Table 2, the pounds removed for each pollutant are taken directly from Table 1 , but because the total list of pollutants is greatly diminished, the total pounds removed under EPA's chosen treatment option drops to 13.8 million pounds, over 300 times less than the loading from Table 1.

\section{Data Not Representative of BPT}

The produced water characterization data from SAIC (1994) (settling data) appear not to be fully representative of best practicable technology (BPT) for the coastal subcategory. BPT is the baseline level of performance from which any increased treatment costs and pollution reduction are considered in the $\mathrm{CE}$ analysis.

EPA (1995b) describes the BPT effluent limits for the coastal subcategory as $48 \mathrm{mg} / 1$ average and $72 \mathrm{mg} / \mathrm{l}$ average. This level of performance can be achieved by using some or all of the following technologies:

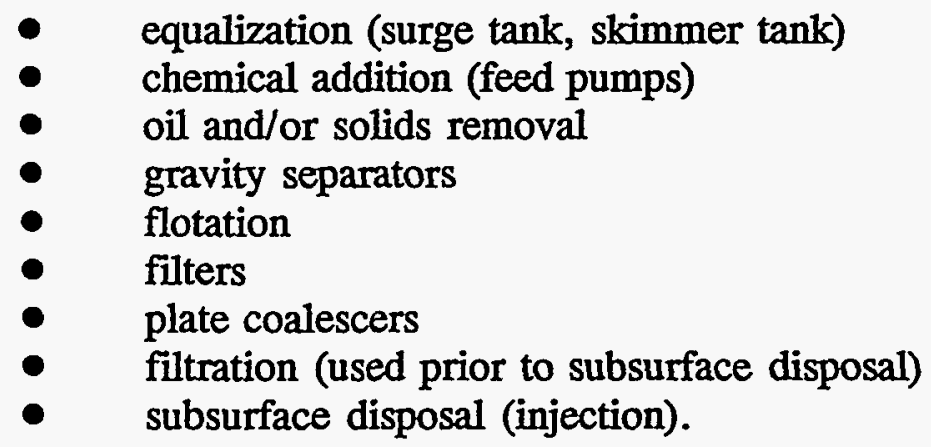

SAIC (1993) described the locations at which samples were collected at the ten sampled facilities. The samples that were used to make up the settling effluent data set were taken at points following gravity settling in various pieces of equipment, but before any additional treatment had taken place. Table 3-3a of SAIC (1994) shows that the mean value for total recoverable oil and grease in settling effluent is about $53 \mathrm{mg} / \mathrm{l}$ and the maximum facility average value for total recoverable oil and grease is about $121 \mathrm{mg} / \mathrm{l}$. Both the average and maximum of the settling effluent data set are less stringent than minimum BPT requirements. If these data are used as the baseline from which pollutant reductions are calculated, the total pollutant reduction load will be overestimated since the average quality of the ten sampled effluents is not as clean as true BPT-quality effluent.

It is not surprising that the settling effluent does not meet BPT standards. Nine of the ten sampled facilities dispose of produced water through underground injection. Since these 
facilities do not discharge produced water to surface waters, they do not need to meet BPT standards before injection. The only additional treatment these facilities would potentially need to provide is filtration to avoid clogging of underground formations during injection. Even filtered produced water effluent would not need to meet BPT standards and may not do so in all cases. Consequently, the data set in SAIC (1994) called "filtration effluent" which consists of samples collected after filtration, may not be representative either.

If the 10-facility data is not fully appropriate for characterizing coastal BPT, the data should be revised. The following paragraphs describe several revisions that should be made to make the 10-facility data more appropriate.

\section{Exclusion of Inappropriate Pollutants}

Some of the pollutants included in the coastal BPT list, such as chlorides, calcium, and magnesium, should not be included in a combined list. Chlorides should not be listed as a pollutant for the coastal subcategory since much of the coastal subcategory is located around saline water and chlorides are a natural component of saline water. Some parts of the coastal subcategory are in direct contact with the Gulf of Mexico and are fully marine. Other parts are in the estuarine transition zone with variable salinities depending on the time of year and precipitation levels. Some portions of the coastal subcategory are in freshwater area. For the most part, these are not currently discharging or will be precluded by state controls from discharging in the near future.

Both calcium and magnesium are common components of natural saline waters and should not be listed as pollutants. EPA has not developed criteria for either of these basic elements. As divalent cations, they contribute to the hardness of the water, but are not toxic substances. Regardless of what data are used, these pollutants and chlorides should be excluded from the analysis.

Many pollutants were detected in only a low percentage of the settling effluent samples analyzed (Table 3-3c of SAIC, 1994). In compiling a revised combined list, any pollutants for which $75 \%$ or more of the data values were below detection level are not included. Twenty-five pollutants are excluded by employing this approach.

The coastal CE analysis, in addition to the individual pollutants listed in EPA (1995a), includes several groups of pollutants (i.e., n-alkanes, steranes, triterpanes, and total xylenes). No analysis for these groups of pollutants is included in SAIC (1994); it is unclear how EPA developed pollutant loading reductions for these groups. There is overlap and double counting by including both these groups and their individual constituent pollutants. For example, nalkanes will measure the same thing as the sum of the 11 individual $n$-alkanes (n-decane through $\mathrm{n}$-triacontane). Likewise, total xylenes will measure the same thing as the sum of $\mathrm{m}$-xylene and 0 - and p-xylene. Consequently, the four groups of pollutants mentioned above are also removed from the pollutant list. 
There is another complicating factor in compiling data sets in which substantial portions of the data are below detection level (BDL). Veil (1994) reviews a report prepared for EPA Region VI that summarized numerous produced water effluent reports in the files of the Louisiana Department of Environmental Quality (Avanti, 1992). Many of the concentrations in the data base were reported as BDL. The authors acknowledged this, and calculated three different means for the collected data for each pollutant, treating the BDL values differently in each case. BDL values were treated as equal to: a) one half of the detection level, b) the detection level, and c) zero. In that particular study, as in EPA (1995a), option a) was selected. This methodology is valid as a general statistical practice, but in some instances, it can yield a misleading average.

In cases where substantial percentages of the values are BDL, a mean based on one half of the detection level can give an inaccurate estimation of the average data value. In these strongly skewed cases, the median value is a better approximation of the average of the data set. Table 3 (taken from Veil, 1994) shows means calculated three different ways and the median for each pollutant. For some pollutants, the means greatly exceed the median.

Unfortunately, SAIC (1994) does not calculate medians. That report calculates means using options b) and c). No calculation of medians is possible without seeing and ranking the actual data. Of the pollutants remaining on the list, only 14 have less than $25 \%$ of their values BDL. Sixteen pollutants have between $25 \%$ and $50 \%$ of their values BDL and 7 pollutants have between $50 \%$ and $74 \%$ of their values BDL. Characterization of pollutant concentrations by using a mean rather than a median when many of the data values are BDL can often overestimate the average concentration. Given the distribution of the data values from SAIC (1994), some of the concentrations and subsequent pounds of pollutant removals may be overestimated.

Table 4 shows the revised list of pollutants and pounds removed. Weighting factors from Versar (1994) and pound equivalents are also shown. The number of pollutants and total pounds removed have both been significantly reduced. The PEs removed have declined by about $10 \%$. section.

Revisions can also be made to the weighting factors. These are discussed in the next

\section{Calculation of Weighting Factors}

Toxicity data are updated periodically in the literature. Good science should be incorporated into regulatory policy where appropriate. However, all new toxicity data should not necessarily be automatically used without verification of the validity of the data. It is also important to consider the use of an analysis before using updated data. For the $\mathrm{CE}$ analysis, which is used to compare the CE of the proposed coastal ELGs to the CE of other promulgated ELGs, changing the nature of the input data, in the form of revised weighting factors. may not be appropriate. 
Tables 1 and 2 calculate PEs by using different sets of weighting factors. Table 1 uses weighting factors calculated for the coastal CE analysis in 1994 (Versar, 1994) while Table 2 uses the weighting factors from the offshore CE analysis which were calculated in 1992 (Versar, 1992). For some pollutants, the weighting factors increased significantly in just two years. For example, the two largest contributors to PEs on Table 1 are radium 228 and benzo(a)pyrene. The weighting factor for radium 228 increased from $1.3 \times 10^{6}$ to $3.5 \times 10^{8}$, a factor of 269 . The weighting factor for benzo(a)pyrene increased from 18.56 to 4,200 , a factor of 226 . As shown in Table 2, when pounds removed are kept the same, but weighting factors are decreased, the relative contributions of radium 228 and benzo(a)pyrene drop from first and second highest contributors to much lower rankings.

The total PEs calculated in Tables 1 and 2 are vastly different. Table 1 , based on the coastal CE analysis, calculates 6.1 million PEs while Table 2, using the same list of pollutants and weighting factors that were used in the offshore CE analysis, calculates 426,000 PEs. analysis.

There are several approaches to assigning weighting factors for a revised coastal CE

- Use the weighting factors calculated by Versar (1994).

- Use the weighting factors calculated by Versar (1992) since that would allow direct comparison to the offshore $\mathrm{CE}$ analysis.

- Start with either the Versar (1992) or (1994) weighting factors, but review the basis for calculating individual weighting factors and recalculate as necessary.

For some pollutants, Versar (1994) calculated coastal weighting factors that were significantly different from the offshore weighting factors (Versar, 1992). In the following sections, the assumptions and data used by Versar (1994) are reviewed and some of the weighting factors are recalculated using alternate assumptions and data. The review focuses on those pollutants that make the largest contribution to total PEs removed.

\section{$\underline{\text { Radium }}$}

EPA has not adopted water quality criteria for radium. In calculating the human health values used in setting weighting factors, Versar (1994) treats radium differently from all other pollutants. This is of great importance since radium makes up nearly $82 \%$ of all produced water PES removed by EPA's chosen treatment option. Without providing an explanation, Versar (1994) uses an entirely different approach for calculating radium weighting factors for the coastal CE analysis than. it did for the offshore CE analysis (Versar, 1992). The human health value for radium in Versar (1994) is derived using the half life, specific activity, slope factor, and bioconcentration factor (BCF). While the approach appears to be accurate, so does the earlier approach used in Versar (1992). As reported above. the weighting factors calculated in 1994 are 269 times larger than those calculated in 1992. For the sake of consistency and 
comparability, it may be appropriate to use the same weighting factors used in the offshore CE analysis -- $1.3 \times 10^{6}$ for both radium 226 and radium 228 .

If changes to the weighting factors are deemed necessary, it may be more appropriate to modify the assumptions and values used in the 1992 approach rather than switch to a totally different approach. Following that philosophy, several modifications are suggested to recalculate the radium weighting factors. Versar (1992) calculated the radium weighting factor through the following equations:

$$
\text { Allowable dose }=2.0 \mathrm{pCi} / 1 \times 2 \mathrm{1} / \mathrm{day}=4.0 \mathrm{pCi} / \text { day }
$$

A human health value was obtained for ingestion of crustacean using a cancer risk of $10^{-5}$ and a bioconcentration factor (BCF) of 140 .

$$
\begin{aligned}
& \text { HHVAL }=\frac{4.0 \mathrm{pCi} / \text { day }}{0.0065 \mathrm{~kg} / \text { day } \times 140 \mathrm{1} / \mathrm{kg}}=4.40 \mathrm{pCi} / 1 \\
& 4.40 \mathrm{pCi} / 1 \times \frac{1 \mathrm{ug}}{1 \times 10^{6} \mathrm{pCi}}=4.4 \times 10^{-6} \mathrm{ug} / 1 \\
& \text { weighting factor }=\frac{5.6 \mathrm{ug} / 1}{4.4 \times 10^{-6} \mathrm{ug} / 1}=1.3 \times 10^{6}
\end{aligned}
$$

Allowable Dose - The radium risk factors used by Versar (1992) were based on EPA's proposed national primary drinking water regulations for radionuclides (56 FR 33050, July 18, 1991). Versar based its risk factors on the maximum contaminant level (MCL) of $2.0 \mathrm{pCi} / 1$ (at a risk level of $10^{-5}$ ). EPA's maximum contaminant level goal (MCLG), a risk-based level, is $4.4 \times 10^{-6} / \mathrm{pCi} / 1$ for radium 226 and $3.8 \times 10^{-6} / \mathrm{pCi} / 1$ for radium 228 (pages $33073-33074$ ). Using a $10^{-5}$ risk level, these yield allowable doses of $2.27 \mathrm{pCi} / 1$ and $2.63 \mathrm{pCi} / 1$ for radium 226 and radium 228 respectively. Note that these are somewhat higher than the value used in equation 2 above; consequently, these recalculated allowable doses will result in lower weighting factors.

Another modification to the risk factors is based on the work of Meinhold et al. (1995) who performed a health risk assessment of produced water discharges into the offshore Gulf of Mexico. These authors suggested that EPA risk factors are overestimated because of EPA's choice of dose-response relationship. To adjust for this, Meinhold et al. (1995) derived a risk factor distribution for radium by assuming that the EPA values represent the upper $90 \%$ confidence limit of a lognormal distribution. Meinhold et al. (1995) use the mean of the lognormal distribution as the basis for their risk assessment. These recalculated risk factors are $1.5 \times 10^{-6} / \mathrm{pCi} / 1$ for radium 226 and $1.0 \times 10^{-6} / \mathrm{pCi} / 1$ for radium 228 . When multiplied by a risk level of $10^{-5}$, the resulting allowable doses are $6.67 \mathrm{pCi} / 1$ for radium 226 and $10.0 \mathrm{pCi} / \mathrm{l}$ for radium 228. These too are larger than the allowable doses considered by Versar (1992) and will result in smaller weighting factors. 
Bioconcentration Factor - Versar (1992) uses a BCF of $140 \mathrm{l} / \mathrm{kg}$, which it attributes to National Academy of Sciences (1971). More recent literature uses a radium BCF of $501 / \mathrm{kg}$ (IAEA, 1982; NCRP, 1991). The lower BCF will result in smaller weighting factors.

Recalculation - Radium weighting factors are recalculated in two ways. Both cases use the lower BCF of $50 \mathrm{l} / \mathrm{kg}$. The difference between the two cases lies in the allowable dose. The first case uses the doses calculated from the MCLG instead of the $2.0 \mathrm{pCi} / 1$ used in equation 2 . These revised weighting factors are $4 \times 10^{5}$ for radium 226 and $3.5 \times 10^{5}$ for radium 228 . The second case uses the doses calculated from Meinhold et al. (1995). These revised weighting factors are $1.37 \times 10^{5}$ for radium 226 and $9.1 \times 10^{4}$ for radium 228 .

Other Considerations - The fish intake per individual is probably higher than the 6.5 g/day assumed by EPA in its CE analyses. For example, Meinhold et al. (1995) estimates a fish intake distribution of $22.6 \mathrm{~g} /$ day mean, $9.08 \mathrm{~g} /$ day median, and $150 \mathrm{~g} /$ day maximum. Such a fish intake distribution would yield higher weighting factors. However, EPA's CE analysis guidance document, Ehrensberger and Rico (1988), requires that EPA use a fish intake of 6.5 $\mathrm{g} /$ day for all $\mathrm{CE}$ analyses. It is important to remember that the $\mathrm{CE}$ analysis is a structured study intended to allow comparison between industries.

Calculation of the radium weighting factors is complicated and unique. It relies on a number of assumptions and data. Versar (1994) chose to use an entirely new approach. This section of the report demonstrates that there are other equally or more valid assumptions and data that can be used to reach alternate, less stringent conclusions.

\section{Benzo(a)pyrene}

Versar (1994) calculated a weighting factor for benzo(a)pyrene of 4,300 based on a human health value of $0.0013 \mathrm{ug} / 1\left(10^{-5}\right.$ risk level) and a saltwater aquatic life protection value of $10 \mathrm{ug} / \mathrm{l}$. In the calculations of PE in the coastal CE analysis, EPA used a weighting factor of 4,200; no explanation was given for the difference between 4,200 and 4,300. In either case, the weighting factor is more stringent than justified. Several years ago, EPA passed a national toxics rule that adopted water quality standards applicable for those states that had not adopted their own water quality standards for toxics (57 FR 60848, December 22, 1992). That rule promulgated a water quality standard for benzo(a)pyrene for human health protection from fish consumption of $0.31 \mathrm{ug} / 1$ (10 $10^{-5}$ risk level).

As shown in equation 1, weighting factors are the sum of two components. The revised human health component of the weighting factor, recalculated using 1992 human health criterion, is 18 . This is added to the aquatic life protection component of the weighting factor, 0.56 , for an overall recalculated weighting factor of 18.56. This is the same approach used in Versar (1992) to calculate the weighting factor used in the offshore CE analysis (also 18.56). 


\section{Boron}

The weighting factor calculated for boron, 0.177 , is the same in both Versar (1992) and Versar (1994). It is based on a freshwater chronic aquatic life protection value of $31.6 \mathrm{ug} / 1$ (Birge et al., 1980) using a single species, rainbow trout. The test method was a 28-day static renewal embryo-larval test using rainbow trout embryos. This type of test is known as a subchronic test and is intended to provide an estimate of chronic toxicity. A similar test using fathead minnows is described in EPA (1985a), except that the fathead minnow test only lasts for 8 days, not 28 days. The rainbow trout test appears to be a scientifically legitimate test, although it has not been officially sanctioned as one of several subchronic tests recommended by EPA (EPA, 1985a).

There are several issues that bear consideration regarding the single piece of data used to calculate the boron weighting factor. Boron is a relatively nontoxic chemical. It is not a priority pollutant and has not been the subject of any EPA water quality criteria development. Adult fish have very high tolerance to boron but developmental stages are more sensitive (Birge and Black, 1977).

Versar (1994) classifies the $31.6 \mathrm{ug} / 1$ value from Birge et al. (1980) as a "lowest reported other value". This is not defined in Versar (1994), but is defined in Versar (1992). The lowest reported other value includes reported values that are not specifically chronic results: Versar (1992) suggests that the LC1 (concentration at which $1 \%$ of the test organisms die) is in reasonable agreement with the no observable effect concentration (NOEC) or the maximum allowable toxicant concentration (MATC), which are normal chronic endpoints. The MATC is the geometric mean of the NOEC and the lowest observable effect concentration (LOEC). In fact, the $31.6 \mathrm{ug} / \mathrm{l}$ value was a calculated LC1. Birge et al. (1980) did not calculate an NOEC.

Normally, an $\mathrm{LCl}$ considers only those organisms that have died. In the case of Birge et al. (1980), the LC1 value included not only dead organisms, but also those with teratogenic abnormalities (severe physical disfigurement).

Versar (1992) states, "The exposure duration for the EC10, LC1, and LC10 toxicity tests is assumed to be the 7-day short-term period unless otherwise specified." As noted above, the test used in Birge et al. (1980) is a 28-day test. It is not possible to determine what incremental mortality and teratogenicity is caused by exposing the rainbow trout to test solutions for 20 more days than fathead minnows would have been exposed, although in general, mortality and teratogenicity increase with prolonged exposure.

Birge et al. (1980) conducted similar tests on 33 different metals and calculated LC1s and $95 \%$ confidence intervals. The range between the upper and lower $95 \%$ confidence intervals for boron was much larger than for any other metal tested. The range for boron was 0.8-191 ug/l (239-fold difference). The next highest range was for zirconium: 2.4-24.1 ug/l (10 fold difference). This suggests that the statistical procedure used to estimate the $\mathrm{LCl}$ for boron could not predict the LCl with very much confidence. This sheds serious doubt on the validity of 
using the data from Birge et al. (1980) for estimating a chronic value for boron.

As described below, the test conditions used by Birge et al. (1980) may present close to a worst case situation for boron. The test used rainbow trout as the test species, boron in the form of boric acid, and the water was relatively hard (100 ppm). Birge and Black (1977) conducted a more thorough study of boron toxicity to three species of fish (rainbow trout, goldfish, and channel catfish) and two amphibians (Fowler's toad and leopard frog). Table 5 shows calculated LC1 values for these five species. Each species was tested at $50 \mathrm{ppm}$ and 200 ppm hardness and with two different forms of boron - boric acid and borax. The rainbow trout was by far the most sensitive species tested. This is important for the coastal oil and gas subcategory. Rainbow trout are cold water, fresh water species and will not occur in any waters potentially receiving produced water from coastal operations. The other fish species and probably the amphibian species tested are much more likely to be found in Gulf of Mexico coastal waters or to be representative of species adapted to the more variable salinity and temperature conditions found in the Gulf of Mexico coastal area. One possible alternate means of estimating a chronic value for boron is to omit the rainbow trout data entirely and use the geometric mean of the LC1s for the next most sensitive species, goldfish. This would be 624 ug/l. The recalculated weighting factor would be 0.009 .

Table 5 also shows that embryos and larvae of all three fish species are more sensitive to boron in the form of boric acid than in the form of borax with one exception. At $50 \mathrm{ppm}$ hardness, the trout are slightly more sensitive to borax than to boric acid (70 ug/l to $100 \mathrm{ug} / \mathrm{l})$. All three fish species are equally or more sensitive to boron at $200 \mathrm{ppm}$ hardness than at $50 \mathrm{ppm}$ hardness. The $31.6 \mathrm{ug} / 1$ value from Birge et al. (1980) was derived using boric acid at a hardness of about $100 \mathrm{ppm}$. Both the form of boron and the higher hardness would tend to result in a lower calculated LC1. EPA has developed water quality criteria for several metals expressed as a function of hardness, but no such relationship is available for boron.

EPA (1985a) provides data comparing LC1s and NOECs for five fathead minnow embryo-larval tests using cadmium. In four of the five tests, the NOEC was at least twice as high as the LC1. In the fifth test, the LC1 was slightly higher than the NOEC. Based on this very limited data set, one could hypothesize that the use of an LC1 from an embryo-larval test to represent a chronic endpoint could potentially result in an overly stringent estimate.

To test this hypothesis, one would ideally calculate an NOEC for the data from both Birge et al. (1980) and Birge and Black (1977). Unfortunately, both sets of data were generated using a single replicate of test animals. The normal procedure used to calculate an NOEC (Dunnett's Procedure, Steel's Many-One Rank Test) requires that the test data have been generated using two or more replicate samples for each tested concentration. One possible approach that can be used to quantify a more justifiable chronic endpoint for boron is to adjust the raw data from Birge and Black (1977) to account for control mortality through Abbott's formula (Finney. 1971). The corrected data can then be visually analyzed to determine which test concentration caused no effect on the organisms. 
Table 6 shows the test results for rainbow trout from Birge and Black (1977) both as raw data and after modification by Abbott's formula. A negative value in the corrected data column means that the observed mortality was below control mortality. Positive values indicate that some mortality was observed in excess of control mortality. For the two tests run using borax, the break point is obvious. At $50 \mathrm{ppm}$ hardness, the NOEC would be $1,000 \mathrm{ug} / 1$ boron (or possibly higher since a test concentration of $5,000 \mathrm{ug} / \mathrm{l}$ boron was not used), and the LOEC would be $10,000 \mathrm{ug} / 1$ boron. At $200 \mathrm{ppm}$ hardness, the NOEC would be 5,000 ug/l boron and the LOEC would be $10,000 \mathrm{ug} / \mathrm{l}$ boron.

For the two tests run using boric acid, interpretation of data is more difficult. In the test run at $50 \mathrm{ppm}$ hardness, acceptable and unacceptable mortality were observed at alternating concentrations. Since the small positive value at $10 \mathrm{ug} / 1$ boron is bounded by larger negative values at $1 \mathrm{ug} / 1$ and $100 \mathrm{ug} / \mathrm{l}$, it is reasonable to consider the $10 \mathrm{ug} / 1$ value as being not significantly different from control mortality. This assumption is consistent with the conclusions drawn concerning the data shown in Table 2B of EPA (1985a). This suggests that the NOEC should be $100 \mathrm{ug} / 1$ boron (or possibly higher since a test concentration of $500 \mathrm{ug} / \mathrm{l}$ boron was not used) and the LOEC $1,000 \mathrm{ug} / 1$ boron. In the test run at $200 \mathrm{ppm}$ hardness, the relatively large positive value at $10 \mathrm{ug} / 1$ boron suggests that this should be the LOEC and the NOEC would be $1 \mathrm{ug} / 1$ boron.

Versar (1992) recommends that MATC values be used as the first choice for estimating a chronic value. Table 7 shows the manually estimated LOECs and NOECs, and the calculated MATCs for the corrected rainbow trout data. The geometric mean of all four MATCs is 387 $\mathrm{ug} / \mathrm{l}$. This is another alternate estimate for the chronic value for boron. The recalculated weighting factor using this approach is 0.0145 .

\section{Ammonia}

Versar (1994) calculates a weighting factor for ammonia based on a saltwater chronic aquatic life protection criterion (54 FR 19227, May 4, 1989). The saltwater criterion for ammonia is not a single value; it is provided as a series of tables that show criteria values at different combinations of salinity, $\mathrm{pH}$, and temperature. The basis for the value chosen by Versar (1994), $690 \mathrm{ug} / \mathrm{l}$, is not given and could represent either of three different sets of conditions: a) $10 \mathrm{~g} / \mathrm{kg}$ salinity, $8.0 \mathrm{pH}$, and $25^{\circ} \mathrm{C}$; b) $10 \mathrm{~g} / \mathrm{kg}, 8.8 \mathrm{pH}$, and $0^{\circ} \mathrm{C}$; or c) $30 \mathrm{~g} / \mathrm{kg}$, $8.2 \mathrm{pH}$, and $20^{\circ} \mathrm{C}$.

It is very difficult to select a single set of environmental conditions to represent the varied coastal subcategory. Condition b) above is not representative of the Gulf of Mexico because of the low temperature. Conditions a) and c) are not representative for coastal Gulf of Mexico because the $\mathrm{pH}$ is too high. While Gulf of Mexico water often has $\mathrm{pH}$ values higher than 8.0, one study of three coastal Louisiana produced water discharge sites found $\mathrm{pH}$ values in the 7.47.8 range at uncontaminated stations. Interstitial waters had even lower $\mathrm{pH}$ values, ranging from about 5.3-6.5 at the uncontaminated reference stations (LUMC, 1989). 
The ammonia criteria are most sensitive to changes in $\mathrm{pH}$, with lower $\mathrm{pH}$ values resulting in higher criteria values. For example, by changing the $\mathrm{pH}$ under condition a) from 8.0 to 7.4, the criterion increases from $690 \mathrm{ug} / \mathrm{l}$ to $2,600 \mathrm{ug} / \mathrm{l}$. If such an adjustment is made, the recalculated weighting factor decreases from 0.0081 to 0.0021 .

\section{Calcium and Magnesium}

As discussed above, both calcium and magnesium are common components of natural waters and should not be listed as pollutants. EPA has not developed criteria for either of these basic elements. As divalent cations, they contribute to the hardness of the water, but are not toxic substances. Versar (1994) estimated a freshwater chronic value for calcium using EPA's AQUIRE data base. The value was reported as "lowest reported other value."

To verify the validity of the data point, AQUIRE was searched to find the original reference, Brown et al. (1973). Brown et al. exposed batches of 25 bluegills and possibly yellow perch to a single concentration of 8 different pollutants. For calcium, the concentration was $200,000 \mathrm{ug} / 1$. The description of the test methodology is vague and confusing, particularly regarding the number of replicates, length of test, and which species were tested. The paper reports that at the tested calcium level, 60 of 100 fish died. Control experiments were conducted, but the results were not presented in the paper. The testing lasted for six months. It is not known if each test lasted six months or if a series of individual tests of shorter duration occurred during a six-month period.

The testing took place during or prior to 1973 . Widely used standard operating practices for conducting aquatic toxicity bioassays did not exist at that time. This study does not appear to have followed many of the basic procedures that must be followed today for toxicity testing (EPA, 1985a and 1985b). It is impossible to assess the accuracy of the mortality endpoint without knowing what the control mortality was during the same period of time. No details are given about control of light, dissolved oxygen, $\mathrm{pH}$, or temperature. It is not known if or what the fish were fed. Considering the age of this test and the many questionable elements concerning test methodology and data analysis, it seems inappropriate to use the value to calculate a weighting factor.

Versar (1994) estimated a chronic freshwater value for magnesium using an acute "lowest observed value" from its ASTER database and assuming an acute to chronic ratio of 10 . To verify the validity of the acute data value, ASTER was searched to find the original reference, de March (1988). The de March paper tested different mixtures of two cations at a time, including magnesium. The only place in the paper that gave any acute toxicity data for magnesium was the following:

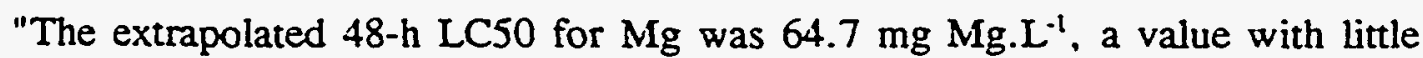
credibility" (de March, 1988). 
If the author of the paper does not place much credence in the $64.7 \mathrm{mg} / \mathrm{l}$ acute endpoint, then it seems inappropriate to use the value to calculate a weighting factor.

Results

The previous sections suggest alternate lists of pollutants to be considered in the $\mathrm{CE}$ analysis and revised weighting factors for several key pollutants. Table 8 lists the various options for each of the decision points. There are at least 144 different possible combinations of options. Calculating and displaying all possible options is not feasible or necessary. To characterize the range of results, the $\$ / \mathrm{PE}$ for the least stringent possible combination of options is compared to the $\$ / \mathrm{PE}$ for the coastal $\mathrm{CE}$ analysis, the most stringent combination of options. For several intermediate scenarios, the $\$ / \mathrm{PE}$ is also calculated. These results are shown in Table 9.

Scenario $A$ is the coastal $C E$ analysis which results in \$4/PE. The least stringent combination is scenario $F$ which results in \$143/PE. Scenario $F$ uses the offshore list of pollutants and the list of offshore weighting factors. The least stringent recalculated weighting factors for radium, benzo(a)pyrene, and boron are substituted. The importance of the recalculated weighting factors is obvious as this scenario is compared to scenario $\mathrm{B}$ (\$52/PE). The difference between the Versar (1994) and Versar (1992) weighting factors, other than those which were recalculated, is minimal. That is the only difference between scenarios $F$ and $G$. Under scenario G, using the Versar (1994) weighting factors, the CE drops to \$131/PE.

Three scenarios use the revised coastal list of pollutants. Scenario C uses the Versar (1994) weighting factors across the board and shows little change from scenario $\dot{A}$ (both at \$4/PE.) However, by changing to the Versar (1992) weighting factors and using recalculated weighting factors for radium, benzo(a)pyrene, boron, and ammonia, the CE increases substantially to \$87/PE for scenario $\mathrm{E}$ and $\$ 92 / \mathrm{PE}$ for scenario $\mathrm{D}$.

\section{Discussion}

By using other equally or more valid assumptions, data, and analysis, a wide range of alternate \$/PEs can be calculated. This report identifies areas in EPA's coastal CE analysis that are subject to different interpretation and provides legitimate alternatives.

One key consideration in selecting the most appropriate set of assumptions, data, and analyses is the purpose and intent of the CE analysis. Is the analysis intended to estimate an independent estimate of the absolute \$/PE or is it intended to show the \$/PE of one industry in relation to all other industries that have been examined? By including the changes made in the coastal CE analysis, EPA has effectively precluded the latter goal. There are several areas in the coastal CE analysis in which consistency is pushed aside. It is particularly obvious since the offshore $\mathrm{CE}$ analysis was conducted just two years ago for effluents that are essentially identical to those considered in the coastal $\mathrm{CE}$ analysis. 
There are several strong indications that EPA is interested in maintaining consistency so that comparison to other industries is possible. Table 4-1 of EPA (1995a) shows the \$/PE for 26 other industries. EPA concludes that its calculated $\$ / P E$ is "well within the range of costeffectiveness values seen for other rules." This conclusion provides a measure of justification that the selected option is reasonable and cost-effective. To further support the goal of consistency, Ehrensberger and Rico (1988), in their guidance on preparing CE analyses, are very careful to require that all costs be converted back to 1981 dollars so that all $\mathrm{CE}$ analyses can be judged on the same terms.

Versar (1994) based many of its weighting factors on values taken from EPA's AQUIRE and ASTER toxicity databases. As was demonstrated by the discussion for the boron, calcium, and magnesium weighting factors, some of this data should not have been used to estimate weighting factors. The analysis in this report only reviewed the weighting factors for those pollutants that had a numerically large contribution to the total PE removed; it is possible that other weighting factors were also overestimated.

All revisions considered in this report affect the number of PEs removed. No attempt has been made to analyze EPA's cost estimate. As stated earlier, in previous oil and gas industry rulemakings, industry and DOE cost estimates exceeded EPA's cost estimates. It is possible that if alternate cost estimates are used in the CE analysis, the overall \$/PE will increase even further.

\section{Conclusions}

EPA appears to consider consistency and comparability as important goals of the CE analysis. With this in mind, perhaps the most appropriate approach is to follow scenario $B$, which uses the same list of pollutants and weighting factors as was used in the 1993 offshore CE analysis. The absolute (not incremental) $\mathrm{CE}$ for scenario $\mathrm{B}, \$ 52 / \mathrm{PE}$, is much higher than the \$4/PE calculated by EPA, and is higher than the \$/PE for most of the other industries listed in EPA (1995a).

If EPA decides that it is willing to change from the approach used in the offshore CE analysis, serious consideration should be given to the alternate lists of pollutants and recalculated weighting factors presented in this report. Scenarios D and E offer well-documented alternative approaches and result in \$92/PE and \$87/PE respectively. These \$/PE are exceeded only by the \$/PEs for the aluminum forming industry (\$121/PE) and the Electronics I industry $(\$ 404 / \mathrm{PE})$. Under these scenarios or the even more costly scenarios $F$ and $\mathrm{G}(\$ 143 / \mathrm{PE}$ and \$131/PE respectively), the coastal produced water requirements for zero discharge in the Gulf of Mexico and offshore limits for Cook Inlet may not be particularly cost-effective.

The incremental \$/PE for the other two waste streams evaluated in the coastal CE analysis are already higher than those for most other industries (drilling wastes - \$292/PE or \$769/PE depending on which option is selected; treatment, workover, and completion fluids $\$ 200$ ). No specific review and critique of these CE analyses was conducted as part of this 
report. However, the $\mathrm{CE}$ analyses for the other coastal waste streams use the same set of weighting factors as the produced water analysis and the key pollutants are similar; consequently, the $\$ / \mathrm{PEs}$ for those analyses are also likely to increase after recalculation. 


\section{$\underline{\text { References }}$}

Avanti, 1992, "Characterization of Produced Water Discharges to the Coastal Subcategory of Louisiana and Texas", draft report prepared by Avanti Corporation for U.S. Environmental Protection Agency, Region VI, July 23.

Birge, W.J. and J.A. Black, 1977, "Sensitivity of Vertebrate Embryos to Boron Compounds," U.S. Environmental Protection Agency, EPA-560/1-76-008, April.

Birge, W.J., J.A. Black, A.G. Westerman, and J.E. Hudson, 1980, "Aquatic Toxicity Tests on Inorganic Elements Occurring in Oil Shale," in Oil Shale Symposium. Sampling, Analysis and Quality Assurance, March 1979, U.S. Environmental Protection Agency, EPA-600/9-80-022, June.

Brown, E.R., L. Keith, J.J. Hazdra, and T. Arndt, 1973, "Tumors in Fish Caught in Polluted Waters: Possible Explanations," in Comparative Leukemia Research 1973, Leukemogenesis, 40:47-57.

de March, B.G.E., (1988), "Acute Toxicity of Binary Mixtures of Five Cations $\left(\mathrm{Cu}^{2+}, \mathrm{Cd}^{2+}\right.$, $\mathrm{Zn}^{2+}, \mathrm{Mg}^{2+}$, and $\mathrm{K}^{+}$) to the Freshwater Amphipod Gammarus lacustris (Sars): Alternative Descriptive Models," Can. J. Fish. Aquat. Sci 45(4):625-633.

Ehrensberger, K. and R. Rico, 1988, "Cost-Effectiveness Analysis for Effluent Guidelines," U.S. Environmental Protection Agency, May.

EPA, 1985a, "Short-Term Methods for Estimating the Chronic Toxicity of Effluents and Receiving Waters to Freshwater Organisms," U.S. Environmental Protection Agency, EPA/600/4-85/014, December.

EPA, 1985b, "Methods for Measuring the Acute Toxicity of Effluents to Freshwater and Marine Organisms," U.S. Environmental Protection Agency, EPA/600/4-85/013, March.

EPA, 1993a, "Development Document for Effluent Limitations Guidelines and New Source Performance Standards for the Offshore Subcategory of the Oil and Gas Extraction Point Source Category," U.S. Environmental Protection Agency, EPA 821-R-93-003, January.

EPA, 1993b, "Cost-Effectiveness Analysis of Final Effluent Limitations Guidelines and Standards for the Offshore Oil and Gas Industry," U.S. Environmental Protection Agency, EPA 821-R-93-005, January.

EPA, 1995a. "Cost-Effectiveness Analysis for Proposed Effluent Limitations Guidelines and Standards for the Coastal Subcategory of the Oil and Gas Extraction Point Sources Category," U.S. Environmental Protection Agency. EPA 821-R-95-010, February. 
EPA, 1995b, "Development Document for Effluent Limitations Guidelines and Standards for the Coastal Subcategory of the Oil and Gas Extraction Point Source Category," U.S. Environmental Protection Agency, EPA 821-R-95-009, February.

Finney, D.J., 1971, Probit Analysis, third edition, Cambridge Press, New York.

IAEA, 1982, "Generic Models and Parameters for Assessing the Environmental Transfer of Radionuclides from routine Releases; Exposure of Critical Groups," Safety Series No. 57, Procedures and Data, International Atomic Energy Agency, Vienna, Austria.

LUMC, 1989, "Environmental Impact of Produced Water Discharges in Coastal Louisiana," prepared by Louisiana Universities Marine Consortium in collaboration with Louisiana State University and A\&M College and Aero-Data Corporation for the Louisiana Division of the MidContinent Oil and Gas Association, July.

Meinhold, A.F., S. Holtzman, and L.D. Hamilton, 1995, "Health Risk Assessment for Radium Discharged Offshore in Produced Water," Society of Petroleum Engineers (SPE) paper 29728, presented at SPE/EPA Exploration \& Production Environmental Conference 95, Houston, March 27-29.

National Academy of Science, 1971, "Radioactivity in the Marine Environment."

NCRP, 1991, "Screening Models for Releases of Radionuclides to Air, Surface Water, and Ground Water," draft report prepared by National Council on Radiation Protection and Measurements, December 11.

Prothro, M., 1993, memorandum from Prothro on "Office of Water Policy and Technical Guidance on Interpretation and Implementation of Aquatic Life Metals Criteria," October 1.

SAIC, 1993, draft "Coastal Oil and Gas Production Sampling Summary Report," prepared by Science Applications International Corporation for U.S. Environmental Protection Agency, April 30 .

SAIC, 1994, "Statistical Analysis of Effluent from Coastal Oil and Gas Extraction Facilities," prepared by Science Applications International Corporation for U.S. Environmental Protection Agency, September 30.

Veil, J.A., 1992, "Review of the Cost-Effectiveness of EPA's Offshore Oil and Gas Effluent Guidelines," in Produced Water, 23-33. New York: Plenum Press.

Veil J.A., 1994, "Analysis of Environmental Regulatory Proposals: It's Your Chance to Influence Policy," in Proceedings of International Petroleum Environmental Conference, sponsored by Univ. of Tulsa and PennWell Publishers, Houston, March. 
Versar, 1992, "Toxic Weighting Factors for Offshore Oil and Gas Extraction Industry Pollutants," prepared by Versar, Inc. for U.S. Environmental Protection Agency, October 15.

Versar, 1994, "Toxic Weighting Factors for Coastal Subcategory of the Oil and Gas Extraction Industry Proposed Effluent Guidelines," prepared by Versar, Inc. for U.S. Environmental Protection Agency, November 2. 
Table 3 - Effects of Choice of Averaging Method and Treatment of Non-Detects in Louisiana DEQ Produced Water Data (from Veil, 1994)

\begin{tabular}{|c|c|c|c|c|c|}
\hline \multirow[b]{2}{*}{ Pollutant } & \multirow[b]{2}{*}{$\begin{array}{c}\% \text { of } \\
\text { values } \\
\text { BDL }\end{array}$} & \multicolumn{4}{|c|}{$\begin{array}{l}\text { Averaging Method } \\
\text { (data expressed as } \mathrm{mg} / \mathrm{l} \text { ) }\end{array}$} \\
\hline & & $\begin{array}{c}\text { Mean } \\
\text { w/ } \\
\text { BDL } \\
=\mathrm{DL}\end{array}$ & $\begin{array}{c}\text { Mean } \\
\mathrm{w} / \\
\mathrm{BDL}= \\
0\end{array}$ & $\begin{array}{c}\text { Mean w/ } \\
\mathrm{BDL}= \\
0.5 \mathrm{DL}\end{array}$ & Median \\
\hline Arsenic & 33 & 18.620 & 0.467 & 10.414. & 0.011 \\
\hline Benzene & 18 & 2.55 & 2.55 & 2.55 & 1.40 \\
\hline Copper & 28 & 0.159 & 0.148 & 0.154 & 0.159 \\
\hline Iron & 4 & $(8.3 .3$ & 835 & 1.93 .3 & 16.4 \\
\hline Lead & 70 & 1.12 .6 & $(2,2.6$ & $\sqrt{12.28}$ & 0.500 \\
\hline Mercury & 65 & 0.181 & 0.80 & 10.38 & 0.0013 \\
\hline Naphthalene & 48 & 0.123 & 0.098 & 0.111 & 0.058 \\
\hline Nickel & 66 & 1.1 .168 & 1.10 & 1.1 .3 & 0.31 \\
\hline $\begin{array}{l}\text { Pentachloro- } \\
\text { phenol }\end{array}$ & 99 & 0.192 & 0.003 & 0.098 & $\begin{array}{c}\text { no value } \\
\text { given }\end{array}$ \\
\hline Phenol & 26 & 3.4. & 3.40. & 3.40 & 0.738 \\
\hline Silver & 64 & 0.059 & 0.041 & 0.050 & 0.071 \\
\hline Thallium & 64 & 0.566 & 0.409 & 0.488 & 1.10 \\
\hline Total Xylenes & 41 & 0.454 & 0.447 & 0.451 & 0.35 \\
\hline Zinc & 17 & 1410 & 109 & 2110 & 0.150 \\
\hline
\end{tabular}

- median is at least 3-fold lower than this mean

BDL - below detection level

DL - detection level 
Table 5 - Estimated LC1 Values in ug/1 for Aquatic Compounds Exposed to Boron Compounds (from Birge and Black, 1977)

\begin{tabular}{|c||c|c|c|c||}
\hline & \multicolumn{2}{|c|}{ Boric Acid } & 50 ppm \\
\hline \hline Hardness & $50 \mathrm{ppm}$ & $200 \mathrm{ppm}$ & 5500 & $200 \mathrm{ppm}$ \\
\hline \hline Channel catfish & 500 & 200 & 1400 & 1700 \\
\hline Goldfish & 600 & 200 & 70 & 900 \\
\hline Rainbow trout & 100 & 1 & - & 70 \\
\hline Fowler's toad & 25000 & 5000 & 5000 & - \\
\hline Leopard frog & 13000 & 22000 & 3000 \\
\hline
\end{tabular}


Table 6 - Rainbow Trout Boron Toxicity Data

Modified by Abbott's Formula to Reflect Control Mortality

(uncorrected data from Birge and Black, 1977)

\begin{tabular}{|c|c|c|c|c|c|c|c|c|}
\hline \multirow[b]{3}{*}{$\begin{array}{l}\text { Concentration } \\
\text { (ug/l) }\end{array}$} & \multicolumn{4}{|c|}{ Boric Acid } & \multicolumn{4}{|c|}{ Borax } \\
\hline & \multicolumn{2}{|c|}{$50 \mathrm{ppm}$ hardness } & \multicolumn{2}{|c|}{200 ppm hardness } & \multicolumn{2}{|c|}{50 ppm hardness } & \multicolumn{2}{|c|}{$200 \mathrm{ppm}$ hardness } \\
\hline & $\%$ killed & $\begin{array}{c}\text { corrected \% } \\
\text { killed }\end{array}$ & $\%$ killed & $\begin{array}{c}\text { corrected \% } \\
\text { killed }\end{array}$ & \% killed & $\begin{array}{c}\text { corrected \% } \\
\text { killed }\end{array}$ & $\%$ killed & $\begin{array}{c}\text { corrected } \% \\
\text { killed }\end{array}$ \\
\hline control & 9 & - & 13 & - & 9 & - & 13 & - \\
\hline 1 & 4 & -5 & 7 & -7 & 3 & -7 & 3 & -11 \\
\hline 10 & 11 & 2 & 21 & 9 & 2 & -8 & 3 & -11 \\
\hline 100 & 4 & -5 & 11 & -2 & 2 & -8 & 2 & -13 \\
\hline 500 & - & - & 19 & 7 & 2 & -8 & 2 & -13 \\
\hline 1,000 & 23 & 15 & 32 & 22 & 4 & -5 & 6 & -8 \\
\hline 5,000 & 16 & 8 & 37 & 28 & - & - & 8 & -6 \\
\hline 10,000 & 3 & -7 & 33 & 23 & 14 & 5 & 15 & 2 \\
\hline 25,000 & 7 & -2 & 54 & 47 & 43 & 37 & - & - \\
\hline 50,000 & 24 & 16 & 37 & 28 & 78 & 75 & 27 & 16 \\
\hline 100,000 & 42 & 36 & 67 & 62 & 100 & 100 & 100 & 100 \\
\hline 200,000 & 73 & 70 & 56 & 49 & 100 & 100 & 100 & 100 \\
\hline
\end{tabular}


Table 7 - Manually Estimated NOECs and LOECs and Calculated MATCs for Boron in ug/l for Tests Using Rainbow Trout (uses corrected data from Table 6)

\begin{tabular}{|c||c|c|c|c|}
\hline \multicolumn{1}{|c||}{} & \multicolumn{2}{|c|}{ Boric Acid } & \multicolumn{2}{c|}{ Borax } \\
\hline \hline Hardness & $50 \mathrm{ppm}$ & $200 \mathrm{ppm}$ & $50 \mathrm{ppm}$ & $200 \mathrm{ppm}$ \\
\hline LOEC & $1,000 \mathrm{ug} / 1$ & $10 \mathrm{ug} / 1$ & $10,000 \mathrm{ug} / 1$ & $10,000 \mathrm{ug} / 1$ \\
\hline NOEC & $100 \mathrm{ug} / 1$ & $1 \mathrm{ug} / 1$ & $1,000 \mathrm{ug} / 1$ & $5,000 \mathrm{ug} / 1$ \\
\hline $\begin{array}{c}\text { MATC } \\
\text { Geometric mean of } \\
\text { MATCs }\end{array}$ & $316.2 \mathrm{ug} / 1$ & $3.16 \mathrm{ug} / 1$ & $3,162 \mathrm{ug} / 1$ & $7,071 \mathrm{ug} / 1$ \\
\hline
\end{tabular}


Table 8 - Options for Decision Points

\section{List of Pollutants}

- coastal CE analysis as shown in Table 1 (75 pollutants)

- offshore CE analysis as shown in Table 2 (30 pollutants)

- revised coastal list as shown in Table 4 (43 pollutants)

\section{Weighting Factors}

- Versar (1994) as starting point

- Versar (1992) as starting point

- recalculated weighting factors for individual pollutants

radium 226

- $\quad 150,000 \quad$ Versar (1994)

- 1,300,000 Versar (1992)

- $400,000 \quad$ recalculated considering MCLG

- $\quad 137,000 \quad$ recalculated considering Meinhold et al (1995)

radium 228

- 350,000,000 Versar (1994)

- 1,300,000 Versar (1992)

- $350,000 \quad$ recalculated considering MCLG

- 91,000 recalculated considering Meinhold et al (1995)

benzo(a)pyrene

- $\quad 4,200$

Versar (1994)

- $\quad 18.56$

Versar (1992)

boron

$-\quad 0.18$
$-\quad 0.009$

- $\quad 0.009$

Versar (1994)

recalculation by deleting trout data

- $\quad 0.0145$

recalculated by considering additional data

ammonia

$\begin{array}{ll}- & 0.0081 \\ - & 0.0021\end{array}$

Versar (1994)

recalculated by considering different salinity 
Table 9 - Summary of Scenarios Using Different Combinations of Pollutant Lists and Weighting Factors

\begin{tabular}{|c|c|c|c|c|c|c|c|c|}
\hline Scenario & Pollutant List & $\begin{array}{l}\text { Baseline } \\
\text { Weighting } \\
\text { Factors }\end{array}$ & Radium & $\begin{array}{l}\text { Benzo(a) } \\
\text { pyrene }\end{array}$ & Boron & Ammonia & PEs Removed & $\$ / P E$ \\
\hline $\begin{array}{c}\text { A. EPA } \\
\text { coastal } \\
\text { ('Table 1) }\end{array}$ & coastal & Versar (1994) & Versar (1994) & Versar (1994) & Versar (1994) & Versar (1994) & $6,108,960$ & 4 \\
\hline $\begin{array}{c}\text { B. EPA } \\
\text { offshore } \\
\text { (Table 2) }\end{array}$ & offshore & Versar (1992) & Versar (1992) & Versar (1992) & Versar (1992) & N/A & 426,617 & 52 \\
\hline $\begin{array}{l}\text { C. Amended } \\
\text { coastal I } \\
\text { ('Table 4) }\end{array}$ & revised & Versar (1994) & Versar (1994) & N/A & Versar (1994) & Versar (1994) & $5,513,405$ & 4 \\
\hline $\begin{array}{l}\text { D. Amended } \\
\text { coastal II }\end{array}$ & revised & Versar (1992) & $\begin{array}{l}\text { recalc. per } \\
\text { Meinhold et } \\
\text { al. (1995) }\end{array}$ & N/A & $\begin{array}{l}\text { recalc. - } \\
\text { deleted trout } \\
\text { data }\end{array}$ & recalc. & 237,927 & 92 \\
\hline $\begin{array}{l}\text { E. Amended } \\
\text { coustal III }\end{array}$ & revised & Versar (1992) & $\begin{array}{l}\text { recalc. } \\
\text { considering } \\
\text { MCLG }\end{array}$ & N/A & $\begin{array}{l}\text { recalc. - used } \\
\text { additional } \\
\text { data }\end{array}$ & recalc. & 252,294 & 87 \\
\hline $\begin{array}{l}\text { F. Amended } \\
\text { offshore } 1\end{array}$ & offshore & Versar (1992) & $\begin{array}{l}\text { recalc. per } \\
\text { Meinhold et } \\
\text { al. (1995) }\end{array}$ & Versar (1992) & $\begin{array}{l}\text { recalc. - } \\
\text { deleted trout } \\
\text { data }\end{array}$ & N/A & 153,065 & 143 \\
\hline $\begin{array}{l}\text { G. Ainended } \\
\text { offshore II }\end{array}$ & offshore & Versar (1994) & $\begin{array}{l}\text { recalc. per } \\
\text { Meinhold et } \\
\text { al. (1995) }\end{array}$ & Versar (1992) & $\begin{array}{l}\text { recalc. - } \\
\text { deleted trout } \\
\text { data }\end{array}$ & N/A & 166,714 & 131 \\
\hline
\end{tabular}

